Int. J. Dev. Biol. 59: 87-93 (2015)

doi: $10.1387 / \mathrm{ijdb} .150045 \mathrm{sg}$

\title{
P63 in health and cancer
}

\author{
STEFANIA GONFLONI*, VALERIO CAPUTO and VALENTINA IANNIZZOTTO \\ Department of Biology, University of Rome "Tor Vergata", Rome, Italy
}

\begin{abstract}
TP63 is the most ancient member of the p53 gene family. The p53 family comprises three transcription factors (p53/p63/p73). They share a high degree of homology and similar domain structure. Yet, they can exist as truncated isoforms. Alternative promoters and splicing sites lead to the generation of several molecules. P53/p63/p73 are important to maintain cell homeostasis. P63 and p73 regulate many p53 target genes. This is due to their common structural features. Both proteins may compensate the loss of p53. This is a common event occurring in more than $50 \%$ of malignancies. Yet, p63 (or p73) has its own role. Studies from p63-null mice have shown the key role of p63 in embryo development. Several reports have supported the p63 role in epidermal development and in skin homeostasis. P63 involvement in heart development is currently being researched. Recent studies have found p63 to be "the guardian of human reproduction". In addition, p63 has an important, even controversial, role in cancer. Here, we provide a general overview of p63 regulation and activity. We discuss emerging concepts about its role in germ line protection, metabolism and cancer.
\end{abstract}

KEY WORDS: p63, genome stability, DNA damage response, metabolism, cancer

\section{Introduction}

P53/p63/p73 are transcription factors. They share structural similarities (Marcel et al., 2011). They have three main domains: the N-terminal Trans-activation domain (TAD), the DNA-binding domain (DBD) and the oligomerization domain (OD) for the formation of functional tetramers (Dotsch et al., 2010). Yet, they exist as various isoforms with distinct functions (De Laurenzi et al., 1998). P53 is an important tumor suppressor gene. P53 acts as a "sensor" of oxidative stress and DNA damage. Activation of p53 leads to cell cycle arrest, senescence or apoptosis, if DNA damage is irreparable. P63 and p73 are necessary to maintain cell homeostasis. Both interact with many p53 target genes (Benard et al., 2003). Yet, p63 (or p73) has its own specific role confirmed by studies with transgenic mice. In this review, we provide a general overview of $\mathrm{p} 63$ regulation and activity.

\section{P63: structure}

The human $p 63$ gene consists of 15 exons spread along more than $250 \mathrm{~Kb}$ on chromosome 3q27 (Murray-Zmijewski et al., 2006). Alternative promoters and splicing sites give rise to six different protein isoforms (TAp63 $\alpha$, TAp63 $\beta$, TAp63 $\gamma, \Delta$ Np63 $\alpha, \Delta$ Np63 $\beta$

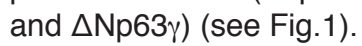

The p63 gene contains two promoters, one located upstream of exon 1 (P1), the other in the intron 3 (P2) (Yang et al., 1998). The former leads to the so-called "trans-activating" isoforms (TAp63). The second promoter generates the "truncated" isoforms $(\Delta \mathrm{Np} 63)$ lacking of the TAdomain. Recent evidence shows another promoter, derived from the fusion of extra exons (U1-U2-U3) with exon 2. This promoter leads to the so-called "GTA"p63 (germ cell-encoded trans-activating p63) isoforms (Beyer et al., 2011).

\section{P63: targets}

TAp63 isoforms bind DNA through p63-responsive elements (p63RE) and p53-responsive elements (p53RE). TAp63 holds functions different from p53. In line with this p63REs are not responsive to p53 isoforms (Murray-Zmijewski et al., 2006, Osada et al., 2005, Sasaki et al., 2005). In contrast to p53, TAp63 $\alpha$ has two extra C-terminal motifs: the Sterile alpha motif (SAM) and the Transactivation inhibitory domain (TID). TID binds in trans the TA domain, leading to inactive TAp63 $\alpha$ dimers. $\triangle$ Np63 isoforms interact with TAp63, leading to negative effects on TAp63 transcriptional activity. $\triangle N p 63$ binds the same DNA region, including the p53RE. Thus $\Delta$ Np63 affects the p53 family activity, exerting a negative

Abbreviations used in this paper: OD, oligomerization domain; TID, transactivation inhibitory domain; SAM, sterile alpha domain; ESC, embryonic stem cell; EMT, epithelial mesenchimal transition; KO, knock out; SKP, skin-derivered precursor.

\footnotetext{
*Address correspondence to: Stefania Gonfloni. Department of Biology, University of Rome "Tor Vergata", Via della Ricerca Scientifica, 00133 Rome, Italy. Tel: +39-06-7259-4319. Fax: +39-06-202-3500. E-mail: Stefania.Gonfloni@uniroma2.it
}

Accepted: 6 May 2015.

ISSN: Online 1696-3547, Print 0214-6282 
effect on them (Bakkers et al., 2002, Barbieri et al., 2005, Benard et al., 2003, Flores et al., 2002, Murray-Zmijewski et al., 2006, Westfall et al., 2003). Yet, $\Delta \mathrm{Np63}$ isoforms are proper transcription factors. They induce different target genes (Dohn et al., 2001, Wu et al., 2003). $\Delta$ Np63 is fundamental for the maintenance of the stem and progenitor cells in stratified epithelial and glandular tissues (Pignon et al., 2013, Senoo et al., 2007). TAp63 has a role in female germ cell preservation (Suh et al., 2006), in protection against cancer metastasis (Melino, 2011, Su et al., 2010) and in senescence (Flores et al., 2005). Inactivation and/or loss of TAp63 may promote a metastatic and an invasive phenotype (Adorno et al., 2009), see Table 1.

Both TAp63 and $\triangle$ Np63 regulate miRNAs, a class of small non-coding RNAs. MiRNAs play a role in post-transcriptional repression of protein-coding genes. Some miRNAs can control p63 expression. P63 promotes miRNAs transcription (Candi et al., 2007). This control can be indirect, since TAp63 activates Dicer, a miRNA processing component. $\triangle$ Np63 represses TAp63induced miRNAs. $\triangle N p 63$ inhibits senescence-specific miRNAs, such as miR-138, miR-181a, miR-181b, and miR-130b, competing with TAp63 (Rivetti di Val Cervo et al., 2012). In head and neck squamous cells carcinoma (HNSCC) $\Delta$ Np63 promotes miR-630 expression. At the same time $\Delta \mathrm{Np} 63$ represses miR-181a, miR519a, and miR-374a.

Following cisplatin, ATM (a sensor kinase of DNA damage) activates $\Delta$ Np63. In this manner $\Delta$ Np63 regulates -through miRNAs expression-, cell survival or death. These miRNAs may control $\Delta$ Np63 expression, because of certain complementarity between their sequence and the 3'UTR of $\triangle$ Np63 mRNA (Huang et al., 2013). $\mathrm{P} 63$ regulates other miRNAs like the miR-200 family
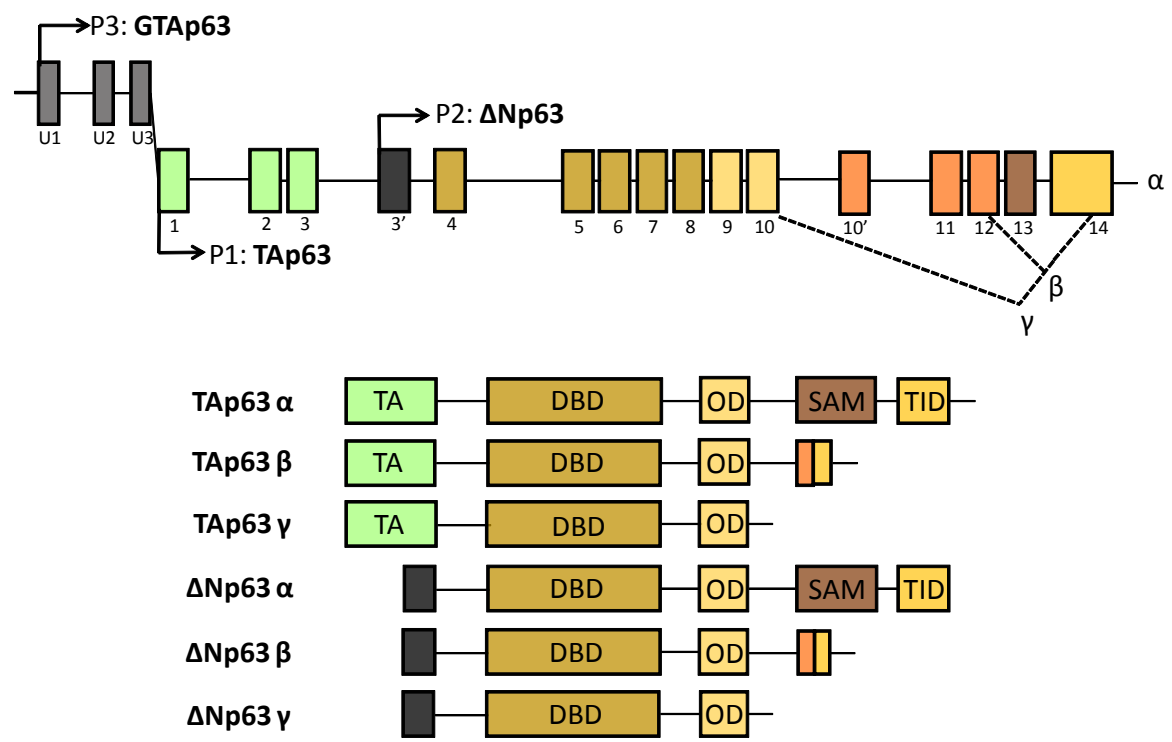

Fig. 1 p63: gene and protein domain structure. The human p63 gene consists of 14 exons spread along more than $250 \mathrm{~Kb}$ on chromosome $3 q 27$. Three main promoters (P1, P2, P3) encode for TAp63, $\triangle N p 63$, and GTAp63 isoforms. P3 derived from the fusion of extra exons (U1-U2-U3) with exon 2. Moreover, alternative splicing sites generate $\alpha, \beta, \gamma$ isoforms, different in the C-terminus. TAp63 isoforms have a Trans-activating domain (TA) encoded by exon 1-2-3. While $\triangle N p 63$ isoforms lack the TA and have 14 unique residues in their N-terminus. TAp63 and $\triangle N p 63$ share a DNA binding domain (DBD) and an oligomerization domain (OD). Only TAp63a and $\triangle N$ p63 share a Sterile alpha domain (SAM) and a Transactivation Inhibitory domain (TID) at the $C$-terminal region. members. The miR-200 family controls the epithelial-mesenchymal transition (EMT). EMT is a typical mechanism to promote cancer invasiveness and metastasis (Gandellini et al., 2012). The miR-200 family represses transcription of ZEB1 (E-cadherin transcriptional repressor) and ZEB2. This leads to inhibition of In breast cancer cell lines, the miR-200 family expression of miR-205. As miR-200, miR-205 has an anti-EMT function in (Tucci et al., 2012). In short, p63 isoforms regulate a wide range of target genes with opposite regulatory outcomes.

\section{P63: regulation}

The p53 family regulates reproduction, DNA repair, metabolic processes, stem cells renewal and changes in epigenetic marks (Costanzo et al., 2014). P53 members undergo extensive posttranslational modifications, which regulate their stability and function. In particular, a wide spectrum of unique modifications and binding proteins, such as PCB1 and HuR, regulate p63 variants at mRNA level (Cho et al., 2013, Jung et al., 2013). Phosphorylation and sumoylation of p63 may induce both p63 activation and/o (Chae et al., 2012). Ubiquitin E3 ligases, kinases, The peptidyl-prolyl isomerase Pin1 may modulate p63 activity. This in turn affects cell survival/proliferation and tumorigenesis i et al., 2013). Pin1 consists of an N-terminal WW domain and a C-terminal peptidyl-prolyl cis/trans isomerase (PPlase) domain. The WW domain binds to phosphor-Ser-Pro (pSP) or phosphor-

Thr-Pro ( $p T P)$ motifs of Pin1 substrates. The C-terminal PPlase domain mediates the cis-trans isomerization of pSP/pTP peptidylprolyl bonds. This results in conformational and functional changes of substrate proteins (Shaw, 2002). Although the contribution of Pin1 in p63 regulation is much less clear, there are evidences for the role of Pin1 in TAp73 $\alpha$ isoforms. Following DNAdamage, a p300-mediated acetylation activates TAp73. This modification increases the interaction of p73 with the YAP1 transcriptional co-factor (Strano et al., 2005). TAp73/YAP complexes bind to the promoters of apoptotic target genes (Costanzo et al., 2002). Of note, TAp73 acetylation requires both conformational changes catalyzed by Pin1 (Mantovani etal., 2004) and c-Abl phosphorylation (Costanzo et al., 2002).

TAp63 $\alpha$ contains 14 putative Pin 1 -binding sites, 8 of which are in all p63 isoforms. In particular, TAp63 aand $\triangle \mathrm{Np} 63 \alpha$ have a unique $\mathrm{C}$-terminal region with 6 putative $\mathrm{Pin} 1$ binding sites. These sites are absent in the p63 $\gamma$ isoforms. Recent evidence shows that Pin1 stabilizes the $\alpha$ isoforms, but not the $\gamma$ variants (Li et al., 2013). This supports that the six Pin1-binding sites in the C-terminal region may play a critical role in p $63 \alpha$ stability. 
A key residue T538 within the SAM domain of $p 63 \alpha$ is necessary for Pin1 interaction. There are two possible mechanisms underlying the Pin1 effect on p63 $\alpha$ stability. T538-Pro is next to the P540PxY543 (PPxY) motif, a site for the ubiquitin E3 ligase WWP1(Li et al., 2008). WWP1 modifies its substrates including p63 $\alpha$ for proteasome-dependent degradation (Li et al., 2008). The isomerization induced by Pin1 alters the conformation of the region surrounding the PPxY motif of p63. This effect regulates the binding of WW domain of E3 ligases (Bellomaria et al., 2012). Or, Pin1 binding to phospho-T538-Pro may prevent WWP1-p63 $\alpha$ interaction ( $\mathrm{Li}$ et al., 2008). The E3 ligase Itch also binds to the same PPxY motif, (Bellomaria et al., 2012). Thus, Pin1 may affect p63-Itch interaction, resulting in p63 $\alpha$ stabilization (Rossi et al., 2006). The final outcome of $p 63 \alpha$ accumulation is the increase of p63 target gene expression.

\section{P63 and skin development}

Both TAp63 and $\triangle$ Np63 are important for skin and epidermal development (reviewed by (Botchkarev and Flores, 2014). Transgenic KO mice for p63 die at birth. They show severe developmental abnormalities, including lack of skin, epidermal appendages and limbs. In mouse embryos, $\Delta$ Np63 is present in the surface epithelium, in teeth and in hair follicles. $\Delta$ Np63 exerts its function in committing immature ectoderm to epidermal lineages. Moreover, $\Delta \mathrm{Np63}$ inhibits mesodermal cell fates to determine a squamous epithelial phenotype in Xenopus and in mouse embryos. TAp63 is present in a set of dermal stem cells known as skin-derived precursors (SKPs). SKPs are capable of clonal and multilineage differentiation. SKPs derive from somites and from neural crest. TAp63 promotes p57kip2 expression, a cell cycle inhibitor, preserving SKPs. TAp63 null mice show a decrease of p57kip2 in tandem with an increasing proliferation and a self-renewal in culture. Restoring of p57kip2 levels rescues TAp63 null phenotype. SKPs and epidermal cells, derived from TAp63 null mice, undergo senescence, a persistent DNA damage and genome instability. Thus, TAp63 preserves both dermal and epidermal stem cells in a functional state with intact genome by promoting skin homeostasis. Further, TAp63 may be responsible of age-related changes that occur in hair follicle compartment.

In general, the p53 family has a key role in aging. Aging is due to a loss of regenerative capacity and homeostasis in the tissues. According to the "stem cell hypothesis for aging" the depletion of stem cells (together with a persistent DNA damage and telomere shortening) is responsible of age-related changes. It is not clear whether senescence driven by TAp63 may prevent cancer in tissues. It remains elusive if such an effect is underlying the role of TAp63 as tumor suppressor.

\section{P63 and heart development}

TAp63 is a key endodermal cardiogenic factor (Paris et al., 2012). TAp63 modulates the specification, the proliferation/survival of cardiac progenitors. Cardiac progenitors migrate from the cardiac crescent. TAp63 may control the conversion of mesocardiac cells in cardiac progenitors. Congenital malformations occur with duplication and deletion of the region 3q27-ter (where the p63 gene is present). Moreover, when aggregated as embryoid bodies, embryonic stem (ES) cells recapitulate in vitro the steps of mesoderm and of cardiac lineages. The appearance of beating areas confirms the presence of mature cardiomyocytes in the cell culture. A study on the role of p63 during ectodermal commitment of pluripotent stem cells shows that TAp63 inactivation prevents the production of beating areas. Specific knockdown of TAp63 variants produced the same outcome. In vivo and in vitro the sequential appearance of specific markers shows cardiac lineages. A significant reduction of early cardiac progenitor markers (tbx5, $n k x 2.5$, isl1) and mature cardiomyocyte markers (troponinT, aactinin and mlc2v) occurs in the absence of TAp63. ChIP-PCR data and chimeric co-culture rescue assays show that TAp63 is only present in endodermal derivatives. TAp63 may stimulate cardiac progenitor lineages. Besides, TAp63 may control the inductive role of the endoderm on cardiac progenitor fate. As a consequence, TAp63 may function as a self-renewal gene for endodermal cardiogenic progenitors. Experiments suggest the existence of feedback mechanism involving Angiomodulin (AGM) and Activin-A. Both proteins are cardiogenic factors required for cardiac commitment of embryonic stem cells (ESCs). TAp63 activates these factors during ESCs cardiogenesis. Both AGM and Activin-A, in turn, modulate TAp63 expression. Yet, alternative pathways may compensate the role of TAp63 in heart development. Two independent studies using TAp63-null mice show different results. In the first transgenic model, Suh et al., reported no embryonic development defect (Suh et al., 2006). Yet, the second $\mathrm{KO}$ mouse strain had a strong proportion of embryonic lethality (Su et al., 2012). These data show that some modifier genes may amplify or neutralize the lack of TAp63, depending on the genetic background of murine strains.

\section{P63 and female germ line}

Germ line protection is essential for the perpetuation of the species during evolution. Maintenance of genomic integrity in somatic cells derives from evolution of germline protection mechanisms. Female germ cells undergo meiosis to generate haploid cells necessary for reproduction. This multiple-step process stops when cells reach a tetraploid state. The extended length of this phase makes the immature oocytes vulnerable. There is necessity for mechanisms ensuring genomic integrity of oocytes. TAp63, although dispensable for oogenesis, is present in primordial and primary follicles. In reserve follicles, TAp63 is present as an inactive dimer. The latter has a low DNA binding affinity. Post-translational modifications of TAp63 regulate a conformation change to active tetramers. Phosphorylation allows the release of the inhibitory interaction of dimers. This in turn increases the affinity for DNA and transcription (Deutsch et al., 2011). This conformational switch of p63 is necessary for oocyte death. TAp63 is phosphorylated/activated following ionized radiation (IR) or cisplatin. In contrast to dimers, active tetramers show high susceptibility to degradation. A binding motif for an E3 ligase is present in the TA domain. Dimers, hiding such a motif, are more stable (Ying et al., 2005). Dimeric molecules ensure a constant level of inactive TAp63. While tetramers have a short half-life. This allows a fine control of the oocyte death in response to stress. Following IR, no induction of pro-apoptotic genes as PUMA and NOXA occurs in primordial follicles from TAp63-null mice. Follicle reserve derived from PUMA or NOXA null mice is resistant to IRinduced apoptosis. The role of TAp63 as a "guardian of human 
reproduction" seems to be an ancestral function within the p53 family. While p63 maintains the ability to preserve female germ cells, p53 gains the "modern" role of genomic stability control for somatic cells. This implies that tumor suppression function and cell cycle control have evolved later (Amelio et al., 2012).

\section{P63 and male germ line}

There is no evidence for a possible engagement of TAp63 in protecting spermatogenic precursors. TAp63 mRNA is present in mouse male germ cells (Petre-Lazar et al., 2007). Yet, specific antibodies fail to detect its protein levels (Suh et al., 2006). Following IR, mouse p63-null testis did not show any significant difference compared with wild type (Petre-Lazar et al., 2007). A new p63 isoform, termed "GTAp63" (germ cell-encoded trans-activating p63) is present in human testis. Yet, GTAp63 is almost undetectable in all other tissues. This protein derives from a more complex 5' region of human TAp63 gene. Three extra upstream exons (U1, U2, U3) are fused with the exon 2 through alternative splicing sites. This generates different $\mathrm{N}$-terminal splicing variants. The most abundant splicing variant derives from fusion of exon U1 with exon 2. GTAp63 differs from the previous described TAp63 isoforms for a 19-residues long N-terminal region. Indeed, it appears that GTAp63 expression is the result of an ERV9 LTR promoter activity. Presumably this isoform derives from an insertion of an endogenous retrovirus, ERV9. The 5' part of exon U1, in fact, overlaps the LTR sequences of ERV9, which are transcribed in testis. Likely this insertion may have enhanced the expression of GTAp63 (Beyer et al., 2011). Upon genotoxic stress, GTAp63 induces transcription of apoptotic p53-responsive genes (PUMA, NOXA, CD95L). This may contribute to the maintenance of spermatozoa genome integrity. It represents also a potential novel tumor suppressor candidate of testicular tumors. Of note, histone deacetylase (HDAC) inhibition restores expression of GTAp63 in testicular carcinomas. In these tumors, p63 expression is often lost (Beyer et al., 2011). It remains elusive whether GTAp63 contributes to p53-dependent apoptosis or acts independently from p53. In the latter case GTAp63 may act like TAp63 in oocytes.

\section{P63 and metabolism}

P53 family members regulate metabolism. This has an important effect for their tumor suppressor activity (Candi et al., 2014). Cancer cells often suffer of starvation. They use aerobic glycolysis as their major source of energy. This metabolic switch (Warburg effect) is crucial for their survival. TAp63 is an important regulator of lipid and glucose metabolism. Transgenic mice (TAp63 null) show defects in fatty acid oxidation and mitochondrial dysfunction. Metabolic disorders such as premature aging, obesity and Type 2 diabetes occur in these mice. TAp63 responds to metformin, the drug used to treat Type 2 diabetes. In particular, TAp63 $\gamma$ variant increases following metformin administration (Su et al., 2012). Moreover, TAp63 null mice are prone to metastatic tumors. This phenotype is like the tissue-specific KO of sirtuin1 (Sirt1), AMPK $\alpha 2$ (one of the subunit of AMP-activated protein kinase, AMPK). A re-expression of such genes (Sirt1 and AMPK $\alpha 2$ ) in a TAp63 null genetic background rescues these mice from metabolic disorders. TAp63 regulates energy metabolism through gene transcription of Sirt1, AMPK $\alpha 2$ and also AMPK-liver kinase B1 (LKB1).

In particular, TAp63 regulates AMPK $\alpha 2$ mRNA levels, but also AMPK $\alpha 2$ activity. Moreover, LKB1, an upstream kinase of AMPK $\alpha 2$, is also a p63 target gene. Upon treatment with metformin, LKB1 levels increase. This results in a metabolic regulation and the same time in an anti-tumoral activity mediated by LKB1 itself. Following starvation and caloric restriction, TAp63 activates Sirt1 transcription. This in turn increases glutaminase 2 (GLS2) levels. GLS2 catalyzes the conversion of glutamine into glutamate, which can be converted to $\alpha$-ketoglutarate. This promotes the production of ATP via the tricarboxylic acid (TCA) cycle, or of glutathione (GSH). The latter is one of the most important antioxidant for the cell. As previously described for AMPK $\alpha 2$, GLS2 levels are regulated by TAp63 via Sirt1. Besides, TAp63 induces GLS2 transcription. TAp63 is able to ensure energy and survival to starved cells. At the same time, TAp63 contributes to the anti-oxidant defense under ROS-related stress conditions. Up-regulation of GLS2 decreases ROS levels within cells. Yet, TAp63 has a role in regulating the expression of pro-oxidant genes, such as REDD1. The latter is a stress-induced factor that is able to sensitize cells to ROS-induced apoptosis. In short, TAp63 activates pro- as well as anti-oxidant proteins depending of cell context. This effect has been already postulated for p53. Indeed, a TAp63-GLS2 axis could regulate ROS-induced apoptosis in a p53-null background.

$\Delta$ Np63 isoform also displays an important contribute to ROSrelated stress. $\Delta$ Np63 regulates glutathione peroxidase 2 (GPx2) expression. GPx2 is an important anti-oxidant Selenium-protein, involved in the conversion of hydrogen peroxide to water. Thus also the expression of $\mathrm{p} 63$ variants may be relevant for regulation of ROS balance. In brief, p63 represents an important regulator of metabolism. This is consistent with p63 activity as a suppressor of tumorigenesis and metastasis.

TABLE 1

\section{DIFFERENT ROLES OF TAP63 AND $\triangle$ NP63 IN SKIN, HEART AND GERM LINE}

\begin{tabular}{|c|c|c|}
\hline & TAp63 & $\Delta$ Np63 \\
\hline$\frac{z}{\text { s }}$ & $\begin{array}{l}\text { Localization: skin-derived precursors, dermal sheath, follicular papilla } \\
\text { Function: } \\
\text { 1) maintenance of dermal precursors } \\
\text { 2) cell quiescence and senescence (aging) } \\
\text { 3) induction of apoptosis }\end{array}$ & $\begin{array}{l}\text { Localization: surface epithelium, developing teeth, epithelial basal layer of hair follicles } \\
\text { Function: } \\
\text { 1) commitment of embryonic ectoderm to epidermal lineage } \\
\text { 2) cell proliferation and self-renewal } \\
\text { 3) inhibition of apoptosis and senescence }\end{array}$ \\
\hline$\underset{\leftarrow}{\stackrel{\leftarrow}{\leftarrow}}$ & $\begin{array}{l}\text { Localization (in embryo): endoderm } \\
\text { Function: } \\
\text { 1) self-renewal of endodermal cardiogenic progenitors } \\
\text { 2) commitment of mesocardiac to cardiac progenitors }\end{array}$ & \\
\hline 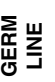 & $\begin{array}{l}\text { Localization: oocytes } \\
\text { Function: } \\
\text { 1) control of oocyte death and preservation of female germ line }\end{array}$ & $\begin{array}{l}\text { Localization: oocytes } \\
\text { Function: } \\
\text { 1) tumor progression in EOC (epithelial ovarian cancer) }\end{array}$ \\
\hline
\end{tabular}




\section{P63 and cancer}

Alteration of p63 expression is linked to tumorigenesis. Although loss of function of p63 is definitely rare compared with the loss of function of p53 in cancer. Evidence shows that TAp63-null mice lead to loss of p53 activity. This effect promotes malignant phenotypes. Heterozygous mice for p63 and p53 have more proneness to tumor in contrast to mice with heterozygosity in p53 (Flores et al., 2005). Indeed a close relationship exists between the p53 family members and the occurrence of cancer. P53 mutants exert negative dominant effects on wild type p53. Yet, they get the ability to inhibit p63 activity through the formation of a complex (Muller and Vousden, 2013). Despite the evidence for p63 as a tumor suppressor, overexpression of p63 occurs in many human cancers (Reis-Filho et al., 2003). Genic amplification on locus $3 q 27$ (where the p63 gene is present) may induce an accumulation of p63 in epithelial cancers. $\Delta$ Np63 plays an essential role in maintenance of skin stem cells and survival. Besides, $\Delta$ Np63 inhibits senescence and apoptosis. These functions are linked to tumor growth in the early stage of cutaneous squamous cell carcinoma. In $80 \%$ of HNSCC (head and neck squamous cell carcinoma) data show an amplification of p63 gene (Massion et al., 2003).

Evidence suggests that $\Delta \mathrm{Np} 63$ represses differentiation in skin. $\triangle \mathrm{Np63}$ regulates many nuclear Vitamin D3 receptor (VDR)-target genes, including (Cyclin-dependent kinase inhibitor (CDKN1A). The latter is a proliferation negative regulator that may be in turn a downstream effector of p53 (Roemer, 2012).

TAp63 isoforms can prevent metastasis and induce senescence (Su et al., 2010). TAp63 is an important metastasis suppressor, acting through different pathways. TAp63 promotes the expression of Sharp1, usually downregulated in metastatic tumors. Sharp1 affects hypoxia induced factor (HIF-1) stability. Sharp1 may need TAp63 $\alpha$ for its activity. While loss of $\Delta \mathrm{Np} 63$ does not influence Sharp1 stability (Piccolo et al., 2013). P63 induces the miR-200 family, whose members can control the epithelial-mesenchymal transition (EMT). EMT is an important step to enable metastasis and invasiveness. $\Delta \mathrm{Np} 63$ is able to activate miR-205, inhibiting the EMT in bladder tumor (Tran et al., 2013). While TAp63 promotes transcription of integrin-recycling genes (D'Aguanno et al., 2014).

In brief, the role of p63 variants in tumorigenesis remains elusive. The model, TAp63 as tumor suppressor while $\Delta N p 63$ as an oncogene, represents a too simplified overview.

\section{P63: a link between genomic stability and metabolism?}

Recent studies in vivo emphasize that p53 tumor suppressor function relies on its ability to regulate metabolism. Data available from mouse models show cooperation between p53 and Sirt1 for genome integrity. Sirt1 modulates p53 transcription-dependent apoptosis. Sirt-1 mediates p53 translocation to mitochondria. P53 translocation from the cytosol to the mitochondria occurs in response to high levels of ROS. P53 accumulation into mitochondria may lead to transcription-independent apoptosis (reviewed in (Gonfloni et al., 2014)). Recent findings from TAp63 or TAp73 null mice highlight the pivotal role of both factors in metabolism. TAp73 null mice develop metabolic defects associated with reduced levels of TAp73 target gene Cox4i1 (cytochrome c oxidase subunit IV isoform 1) (Rufini et al., 2013). Consequences of these disorders are mitochondrial respiration defects and increase in ROS production. This results in premature aging. Furthermore, the energy sensor kinase AMPK induces TAp73. TAp73 protein half-life increases in the nucleus after pharmacologic stimulation of AMPK by AICAR in HCT116 and HCT p53-/- cells. Prolonged activation of AMPK leads to apoptosis-p73 dependent, but only in p53-expressing cells. TAp73 is essential for p53 stabilization during AMPK activation. Yet, TAp73 is dispensable for p53 activation following DNA damage (Adamovich et al., 2014). A recent study shows that TAp63 controls various aspects of metabolism. This in turn may contribute to TAp73 tumor suppressor function.

Elsa Flores and colleagues noticed that TAp63 null mice develop many metabolic defects into adulthood. TAp63 null mice have lipid deposits in various tissues, even when food intake is comparable. Besides, TAp63 null mice show insulin resistance and glucose intolerance, leading to obesity (Napoli and Flores, 2013). These metabolic defects are in tandem with low levels of TAp63 target genes. Indeed, ChIP- and gene reporter data show that TAp63 is a transcriptional activator of Sirt1, AMPK $\alpha 2$ and LBK1 (Fig.2).

Emerging evidence shows that DNA damage induces metabolic changes. These changes increase nucleotide precursors synthesis, promoting DNA repair (Jeong et al., 2014). Metabolites (including acetyl-CoA, NAD+, FAD/ $\alpha$-ketoglutarate) are necessary for the

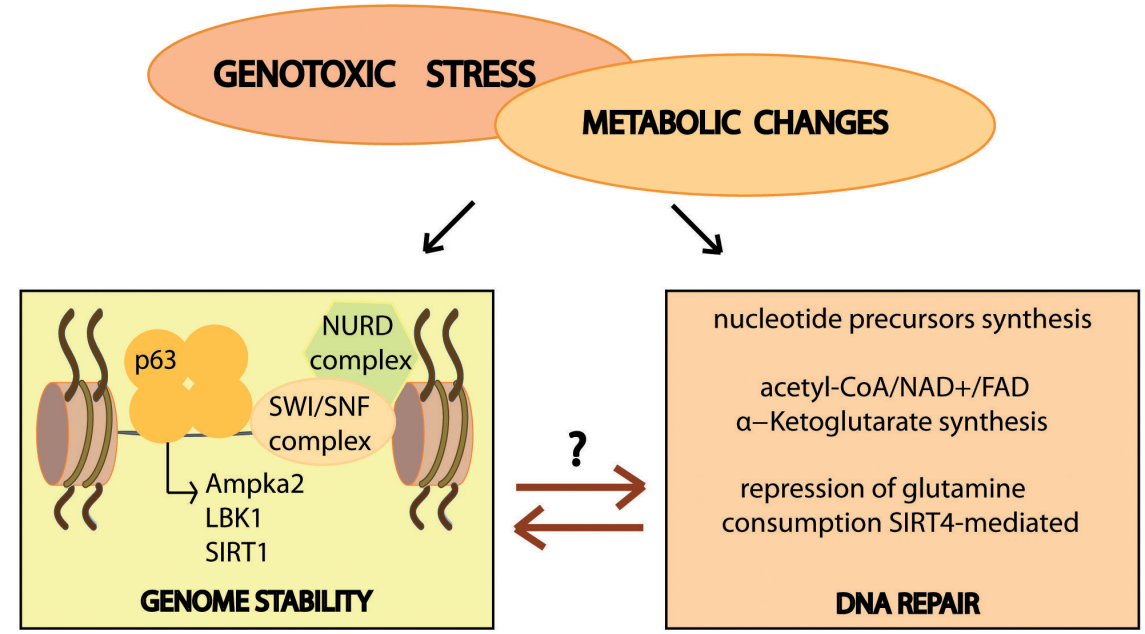

Fig. 2 Genotoxic stress induces metabolic changes affecting DNA repair. Metabolites (including acetylCoA/NAD+/FAD/a-Ketoglutarate are essential for the activity of histone-modifications complexes (such as NURD-SWI/SNF). Genotoxic stress induces the activity of the mitochondrial protein sirtuin 4 (Sirt4). This in turn reduces glutamine consumption and the levels of tricarboxylic acid (TCA) cycle intermediates. Likely, Sirt4 preserves genome integrity upon genotoxic stress by regulating glutamine metabolism. Following DNA damage, p63 is phosphorylated by sensor kinases. These modifications cause a conformational change to tetramers. TAp63 tetramers bind DNA, promoting the transcription of target genes, such as AMPKa2 lone of AMP-activated kinase, AMPK), AMPK-liver kinase B1 (LBK1), and sirtuin1 (Sirt1). 
activity of histone modification enzymes. NAD+ is required for deacetylation or polyADP-ribosylation of chromatin. Instead, FAD $/ \alpha-$ ketoglutarate and S-adenosyl-L-methionine modulate reversible methylation of histones. Further proofs of the connection between metabolic flux and genome stability come from Jeong and colleagues. Genotoxic stress induces high levels of the mitochondrial protein sirtuin 4 (Sirt4). This in turn reduces glutamine consumption and the levels of tricarboxylic acid (TCA) cycle intermediates in primary and tumor cell lines. Loss of Sirt4 expression leads to an altered cell-cycle arrest and accumulation of DNA damage. Likely, Sirt4 may preserve genome stability following genotoxic stress by regulating glutamine metabolism.

In conclusion, it is evident that regulation of energetic metabolism is a main function of the p53 family of genes (Rufini et al., 2013).

\section{Conclusions}

The p53 family has an important role in cancer development and in metabolism. Yet, the molecular details of the interplay between p53/p63/p73 isoforms remain elusive. Recent data from Morgan and colleagues suggest that $p 53$ binds its responsive elements in many chromatin contexts. Moreover, p53 (and likely p63) acts as pioneer factor. Since p53 can bind DNA within closed chromatin, lacking other chromatin features of enhancers (Sammons et al., 2014). This intrinsic property of p53 (and of p63) suggests unique chromatin-based regulatory mechanisms. These mechanisms may regulate the 53 family-mediated responses in a specific cell lineage.

The function of p63 isoforms in the skin is still object of investigation. Transgenic mouse models highlight the critical role of p63 in stem cell maintenance and renewal. Besides, p63 has a role in DNA damage stress response. Recent findings show an important role of 633 in metabolism. These findings point out future directions. Besides, they bring more insights to the p63 function in different signaling contexts. Yet, it remains elusive whether and at what extent TAp63 controls metabolism and maintenance of genomic integrity. This will be relevant for the development and design of targeted therapies for cancer patients.

\section{Acknowledgements}

This work was supported by AIRC (Grant N.11344) to SG. We thank Marc Diederich and Gianni Cesareni for their valuable support.

\section{References}

ADAMOVICH, Y., ADLER, J., MELTSER, V., REUVEN, N. and SHAUL, Y. (2014). AMPK couples p73 with p53 in cell fate decision. Cell Death Differ21: 1451-1459.

ADORNO, M., CORDENONSI, M., MONTAGNER, M., DUPONT, S., WONG, C., HANN, B., SOLARI, A., BOBISSE, S., RONDINA, M.B., GUZZARDO, V. et al., (2009). A Mutant-p53/Smad complex opposes p63 to empower TGFbeta-induced metastasis. Cell 137: 87-98.

AMELIO, I., GRESPI, F., ANNICCHIARICO-PETRUZZELLI, M. and MELINO, G. (2012). p63 the guardian of human reproduction. Cell Cycle 11: 4545-4551.

BAKKERS, J., HILD, M., KRAMER, C., FURUTANI-SEIKI, M. and HAMMERSCHMIDT, M. (2002). Zebrafish DeltaNp63 is a direct target of Bmp signaling and encodes a transcriptional repressor blocking neural specification in the ventral ectoderm. Dev Cell 2: 617-627.

BARBIERI, C.E., PEREZ, C.A., JOHNSON, K.N., ELY, K.A., BILLHEIMER, D. and PIETENPOL, J.A. (2005). IGFBP-3 is a direct target of transcriptional regulation by DeltaNp63alpha in squamous epithelium. Cancer Res 65: 2314-2320.

BELLOMARIA, A., BARBATO, G., MELINO, G., PACI, M. and MELINO, S. (2012). Recognition mechanism of $\mathrm{p} 63$ by the E3 ligase Itch: novel strategy in the study and inhibition of this interaction. Cell Cycle 11: 3638-3648.

BENARD, J., DOUC-RASY, S. and AHOMADEGBE, J.C. (2003). TP53 family members and human cancers. Hum Mutat 21: 182-191.

BEYER, U., MOLL-ROCEK, J., MOLL, U.M. and DOBBELSTEIN, M. (2011). Endogenous retrovirus drives hitherto unknown proapoptotic p63 isoforms in the male germ line of humans and great apes. Proc Natl Acad Sci USA 108: 3624-3629.

BOTCHKAREV, V.A. and FLORES, E.R. (2014). p53/p63/p73 in the epidermis in health and disease. Cold Spring Harb Perspect Med 4.

CANDI, E., AGOSTINI, M., MELINO, G. and BERNASSOLA, F. (2014). How the TP53 family proteins TP63 and TP73 contribute to tumorigenesis: regulators and effectors. Hum Mutat 35: 702-714.

CANDI, E., DINSDALE, D., RUFINI, A., SALOMONI, P., KNIGHT, R.A., MUELLER, M., KRAMMER, P.H. and MELINO, G. (2007). TAp63 and DeltaNp63 in cancer and epidermal development. Cell Cycle 6: 274-285.

CHAE, Y.S., KIM, H., KIM, D., LEE, H. and LEE, H.O. (2012). Cell density-dependent acetylation of DeltaNp63alpha is associated with p53-dependent cell cycle arrest. FEBS Lett 586: 1128-1134

CHO, S.J., JUNG, Y.S. and CHEN, X. (2013). Poly (C)-binding protein 1 regulates p63 expression through mRNA stability. PLoS One 8: e71724.

COSTANZO, A., MERLO, P., PEDICONI, N., FULCO, M., SARTORELLI, V., COLE, P.A., FONTEMAGGI, G., FANCIULLI, M., SCHILTZ, L., BLANDINO, G. et al., (2002). DNA damage-dependent acetylation of $p 73$ dictates the selective activation of apoptotic target genes. Mol Cell 9: 175-186.

COSTANZO, A., PEDICONI, N., NARCISI, A., GUERRIERI, F., BELLONI, L., FAUSTI, F., BOTTI, E. and LEVRERO, M. (2014). TP63 and TP73 in cancer, an unresolved "family" puzzle of complexity, redundancy and hierarchy. FEBS Lett588: 2590-2599.

D'AGUANNO, S., BARCAROLI, D., ROSSI, C., ZUCCHELLI, M., CIAVARDELLI, D., CORTESE, C., DE COLA, A., VOLPE, S., D'AGOSTINO, D., TODARO, M. et al., (2014). p63 isoforms regulate metabolism of cancer stem cells. $J$ Proteome Res 13: 2120-2136.

DE LAURENZI, V., COSTANZO, A., BARCAROLI, D., TERRINONI, A., FALCO, M., ANNICCHIARICO-PETRUZZELLI, M., LEVRERO, M. and MELINO, G. (1998). Two new p73 splice variants, gamma and delta, with different transcriptional activity. J Exp Med 188: 1763-1768.

DEUTSCH, G.B., ZIELONKA, E.M., COUTANDIN, D., WEBER, T.A., SCHAFER, B., HANNEWALD, J., LUH, L.M., DURST, F.G., IBRAHIM, M., HOFFMANN, J. et al., (2011). DNA damage in oocytes induces a switch of the quality control factor TAp63alpha from dimer to tetramer. Cell 144: 566-576.

DOHN, M., ZHANG, S. and CHEN, X. (2001). p63alpha and DeltaNp63alpha can induce cell cycle arrest and apoptosis and differentially regulate $\mathrm{p} 53$ target genes. Oncogene 20: 3193-3205

DOTSCH, V., BERNASSOLA, F., COUTANDIN, D., CANDI, E. and MELINO, G. (2010) p63 and p73, the ancestors of p53. Cold Spring Harb Perspect Biol 2: a004887.

FLORES, E.R., SENGUPTA, S., MILLER, J.B., NEWMAN, J.J., BRONSON, R. CROWLEY, D., YANG, A., MCKEON, F. and JACKS, T. (2005). Tumor predisposition in mice mutant for $\mathrm{p} 63$ and p73: evidence for broader tumor suppressor functions for the p53 family. Cancer Cell 7: 363-373.

FLORES, E.R., TSAI, K.Y., CROWLEY, D., SENGUPTA, S., YANG, A., MCKEON, F. and JACKS, T. (2002). p63 and p73 are required for p53-dependent apoptosis in response to DNA damage. Nature 416: 560-564.

GANDELLINI, P., PROFUMO, V., CASAMICHELE, A., FENDERICO, N., BORRELLI, S., PETROVICH, G., SANTILLI, G., CALLARI, M., COLECCHIA, M., POZZI, S. et al., (2012). miR-205 regulates basement membrane deposition in human prostate: implications for cancer development. Cell Death Differ 19: 1750-1760.

GONFLONI, S., IANNIZZOTTO, V., MAIANI, E., BELLUSCI, G., CICCONE, S. and DIEDERICH, M. (2014). P53 and Sirt1: Routes of metabolism and genome stability. Biochem Pharmacol 92: 149-56.

GREGORY, P.A., BERT, A.G., PATERSON, E.L., BARRY, S.C., TSYKIN, A., FARSHID, G., VADAS, M.A., KHEW-GOODALL, Y. and GOODALL, G.J. (2008). The miR200 family and miR-205 regulate epithelial to mesenchymal transition by targeting ZEB1 and SIP1. Nat Cell Biol 10: 593-601.

HUANG, Y., KESSELMAN, D., KIZUB, D., GUERRERO-PRESTON, R. and RATOVITSKI, E.A. (2013). Phospho-DeltaNp63alpha/microRNA feedback regulation in squamous carcinoma cells upon cisplatin exposure. Cell Cycle 12: 684-697.

JEONG, S.M., XIAO, C., FINLEY, L.W., LAHUSEN, T., SOUZA, A.L., PIERCE, K., LI, Y.H., WANG, X., LAURENT, G., GERMAN, N.J. et al., (2014). SIRT4 has tumor- 
suppressive activity and regulates the cellular metabolic response to DNA damage by inhibiting mitochondrial glutamine metabolism. Cancer Cell 23: 450-463.

JUNG, Y.S., QIAN, Y., YAN, W. and CHEN, X. (2013). Pirh2 E3 ubiquitin ligase modulates keratinocyte differentiation through p63. J Invest Dermatol 133: 1178-1187.

LI, C., CHANG, D.L., YANG, Z., QI, J., LIU, R., HE, H., LI, D. and XIAO, Z.X. (2013). Pin1 modulates p63alpha protein stability in regulation of cell survival, proliferation and tumor formation. Cell Death Dis 4: e943.

LI, C. and XIAO, Z.X. (2014). Regulation of p63 protein stability via ubiquitin-proteasome pathway. Biomed Res Int 2014: 175721

LI, Y., ZHOU, Z. and CHEN, C. (2008). WW domain-containing E3 ubiquitin protein ligase 1 targets p63 transcription factor for ubiquitin-mediated proteasomal degradation and regulates apoptosis. Cell Death Differ 15: 1941-1951.

MANTOVANI, F., PIAZZA, S., GOSTISSA, M., STRANO, S., ZACCHI, P., MANTOVANI, R., BLANDINO, G. and DEL SAL, G. (2004). Pin1 links the activities of c-Abl and p300 in regulating p73 function. Mol Cell 14: 625-636.

MARCEL, V., DICHTEL-DANJOY, M.L., SAGNE, C., HAFSI, H., MA, D., ORTIZCUARAN, S., OLIVIER, M., HALL, J., MOLLEREAU, B., HAINAUT, P. etal., (2011). Biological functions of p53 isoforms through evolution: lessons from animal and cellular models. Cell Death Differ 18: 1815-1824.

MASSION, P.P., TAFLAN, P.M., JAMSHEDUR RAHMAN, S.M., YILDIZ, P., SHYR, Y., EDGERTON, M.E., WESTFALL, M.D., ROBERTS, J.R., PIETENPOL, J.A., CARBONE, D.P. et al., (2003). Significance of p63 amplification and overexpression in lung cancer development and prognosis. Cancer Res 63: 7113-7121.

MELINO, G. (2011). p63 is a suppressor of tumorigenesis and metastasis interacting with mutant p53. Cell Death Differ 18: 1487-1499.

MULLER, P.A. and VOUSDEN, K.H. (2013). p53 mutations in cancer. Nat Cell Biol 15: 2-8.

MURRAY-ZMIJEWSKI, F., LANE, D.P. and BOURDON, J.C. (2006). p53/p63/p73 isoforms: an orchestra of isoforms to harmonise cell differentiation and response to stress. Cell Death Differ 13: 962-972.

NAPOLI, M. and FLORES, E.R. (2013). The family that eats together stays together: new p53 family transcriptional targets in autophagy. Genes Dev 27: 971-974.

OSADA, M., PARK, H.L., NAGAKAWA, Y., YAMASHITA, K., FOMENKOV, A., KIM, M.S., WU, G., NOMOTO, S., TRINK, B. and SIDRANSKY, D. (2005). Differential recognition of response elements determines target gene specificity for p53 and p63. Mol Cell Biol 25: 6077-6089.

PARIS, M., ROULEAU, M., PUCEAT, M. and ABERDAM, D. (2012). Regulation of skin aging and heart development by TAp63. Cell Death Differ 19: 186-193.

PETRE-LAZAR, B., LIVERA, G., MORENO, S.G., TRAUTMANN, E., DUQUENNE, C., HANOUX, V., HABERT, R. and COFFIGNY, H. (2007). The role of p63 in germ cell apoptosis in the developing testis. J Cell Physiol 210: 87-98.

PICCOLO, S., ENZO, E. and MONTAGNER, M. (2013). p63, Sharp1, and HIFs: master regulators of metastasis in triple-negative breast cancer. Cancer Res 73: $4978-4981$

PIGNON, J.C., GRISANZIO, C., GENG, Y., SONG, J., SHIVDASANI, R.A. and SIGNORETTI, S. (2013). p63-expressing cells are the stem cells of developing prostate, bladder, and colorectal epithelia. Proc NatlAcad SciUSA 110:8105-8110.

REIS-FILHO, J.S., SIMPSON, P.T., MARTINS, A., PRETO, A., GARTNER, F. and SCHMITT, F.C. (2003). Distribution of p63, cytokeratins 5/6 and cytokeratin 14 in 51 normal and 400 neoplastic human tissue samples using TARP-4 multi-tumor tissue microarray. Virchows Arch 443: 122-132.

RIVETTI DI VAL CERVO, P., LENA, A.M., NICOLOSO, M., ROSSI, S., MANCINI, M., ZHOU, H., SAINTIGNY, G., DELLAMBRA, E., ODORISIO, T., MAHE, C. et al., (2012). p63-microRNA feedback in keratinocyte senescence. Proc Natl Acad Sci USA 109: 1133-1138.
ROEMER, K. (2012). Notch and the p53 clan of transcription factors. Adv Exp Med Biol 727: 223-240.

ROSSI, M. AQEILAN, R.I., NEALE, M., CANDI, E, SALOMONI, P., KNIGHT, R.A., CROCE, C.M. and MELINO, G. (2006). The E3 ubiquitin ligase Itch controls the protein stability of p63. Proc Natl Acad Sci USA 103: 12753-12758.

RUFINI, A., TUCCI, P., CELARDO, I. and MELINO, G. (2013). Senescence and aging: the critical roles of p53. Oncogene 32: 5129-5143.

SAMMONS, M.A., ZHU, J., DRAKE, A.M. and BERGER, S.L. (2014). TP53 engagement with the genome occurs in distinct local chromatin environments via pioneer factor activity. Genome Res 25: 179-88.

SASAKI, Y., NAISHIRO, Y., OSHIMA, Y., IMAI, K., NAKAMURA, Y. and TOKINO, T. (2005). Identification of pigment epithelium-derived factor as a direct target of the p53 family member genes. Oncogene 24: 5131-5136.

SENOO, M., PINTO, F., CRUM, C.P. and MCKEON, F. (2007). p63 Is essential for the proliferative potential of stem cells in stratified epithelia. Cell 129: 523-536.

SHAW, P.E. (2002). Peptidyl-prolyl isomerases: a new twist to transcription. EMBO Rep 3: 521-526.

STRANO, S., MONTI, O., PEDICONI, N., BACCARINI, A., FONTEMAGGI, G., LAPI, E., MANTOVANI, F., DAMALAS, A., CITRO, G., SACCHI, A. et al., (2005). The transcriptional coactivator Yes-associated protein drives p73 gene-target specificity in response to DNA Damage. Mol Cell 18: 447-459.

SU, X., CHAKRAVARTI, D., CHO, M.S., LIU, L., GI, Y.J., LIN, Y.L., LEUNG, M.L., EL-NAGGAR, A., CREIGHTON, C.J., SURAOKAR, M.B. et al., (2010). TAp63 suppresses metastasis through coordinate regulation of Dicer and miRNAs. Nature 467: 986-990.

SU, X., GI, Y.J., CHAKRAVARTI, D., CHAN, I.L., ZHANG, A., XIA, X., TSAI, K.Y. and FLORES, E.R. (2012). TAp63 is a master transcriptional regulator of lipid and glucose metabolism. Cell Metab 16: 511-525.

SUH, E.K., YANG, A., KETTENBACH, A., BAMBERGER, C., MICHAELIS, A.H., ZHU, Z., ELVIN, J.A., BRONSON, R.T., CRUM, C.P. and MCKEON, F. (2006) p63 protects the female germ line during meiotic arrest. Nature 444: 624-628.

TRAN, M.N., CHOI, W., WSZOLEK, M.F., NAVAI, N., LEE, I.L., NITTI, G., WEN, S., FLORES, E.R., SIEFKER-RADTKE, A., CZERNIAK, B. et al., (2013). The p63 protein isoform DeltaNp63alpha inhibits epithelial-mesenchymal transition in human bladder cancer cells: role of MIR-205. J Biol Chem 288: 3275-3288.

TUCCI, P., AGOSTINI, M., GRESPI, F., MARKERT, E.K., TERRINONI, A., VOUSDEN, K.H., MULLER, P.A., DOTSCH, V., KEHRLOESSER, S., SAYAN, B.S. et al., (2012). Loss of p63 and its microRNA-205 target results in enhanced cell migration and metastasis in prostate cancer. Proc Natl Acad Sci USA 109: 15312-15317.

WESTFALL, M.D., MAYS, D.J., SNIEZEK, J.C. and PIETENPOL, J.A. (2003). The Delta Np63 alpha phosphoprotein binds the p21 and 14-3-3 sigma promoters in vivo and has transcriptional repressor activity that is reduced by Hay-Wells syndrome-derived mutations. Mol Cell Biol 23: 2264-2276.

WU, G., NOMOTO, S., HOQUE, M.O., DRACHEVA, T., OSADA, M., LEE, C.C., DONG, S.M., GUO, Z., BENOIT, N., COHEN, Y. et al., (2003). DeltaNp63alpha and TAp63alpha regulate transcription of genes with distinct biological functions in cancer and development. Cancer Res 63: 2351-2357.

YANG, A., KAGHAD, M., WANG, Y., GILLETT, E., FLEMING, M.D., DOTSCH, V., ANDREWS, N.C., CAPUT, D. and MCKEON, F. (1998). p63, a p53 homolog at 3q27-29, encodes multiple products with transactivating, death-inducing, and dominant-negative activities. Mol Cell 2: 305-316.

YING, H., CHANG, D.L., ZHENG, H., MCKEON, F. and XIAO, Z.X. (2005). DNAbinding and transactivation activities are essential for TAp63 protein degradation. Mol Cell Biol 25: 6154-6164. 


\section{Further Related Reading, published previously in the Int. J. Dev. Biol.}

Revisiting DNA damage repair, p53-mediated apoptosis and cisplatin sensitivity in germ cell tumors Francesca Cavallo, Darren R. Feldman and Marco Barchi

Int. J. Dev. Biol. (2013) 57: 273-280

Distribution of p53 binding protein 1 (53BP1) and phosphorylated H2A.X during mouse preimplantation development in the absence of DNA damage

Céline Ziegler-Birling, Anne Helmrich, Làszlò Tora and Maria-Elena Torres-Padilla

Int. J. Dev. Biol. (2009) 53: 1003-1011

The role of Akt signalling in the mammalian ovary

Sandra Cecconi, Annunziata Mauro, Valerio Cellini and Felice Patacchiola Int. J. Dev. Biol. (2012) 56: 809-817

Life-giving caspases: revealing new roles during mouse embryo preimplantation development

Dolores Busso, Calixto Dominguez, Tomas Perez-Acle and Ricardo D. Moreno Int. J. Dev. Biol. (2010) 54: 857-865

The role of p53 in vivo during skeletal muscle post-natal development and regeneration: studies in p53 knockout mice

Jason D White, Collins Rachel, Royce Vermeulen, Marilyn Davies and Miranda D Grounds Int. J. Dev. Biol. (2002) 46: 577-582

5 yr ISI Impact Factor $(2013)=2.879$
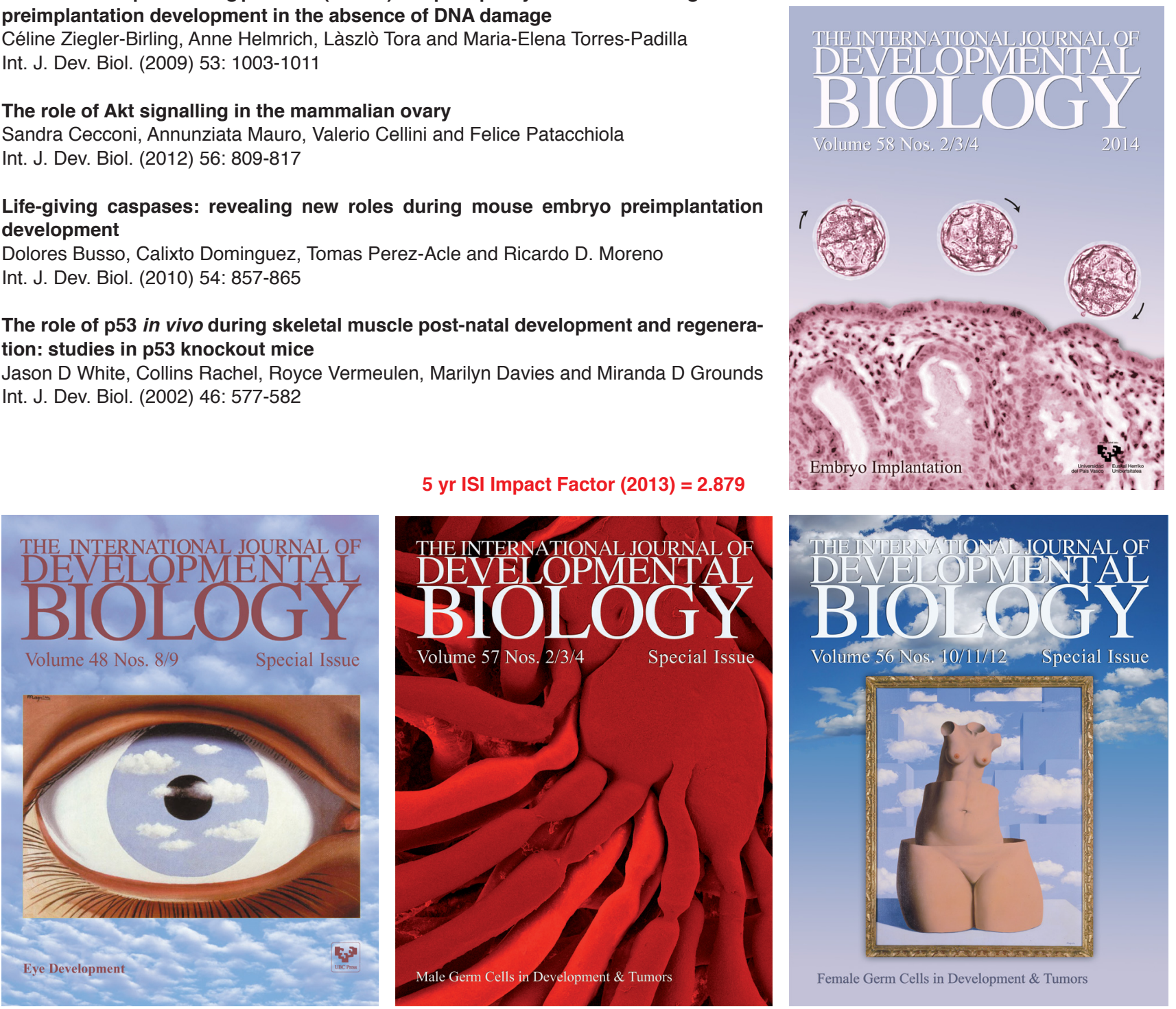